\title{
Household and individual risk factors of anaemia among under-5 children in Lesotho
}

\author{
Teboho Letuka, Sasha Frade
}

Faculty of Humanities, Demography and Population Studies, Schools of Social Sciences and Public Health, University of the Witwatersrand, Private bag 3 Wits, 2050, Johannesburg, South Africa.

\begin{abstract}
Background: Anaemia among under-5 children is a major public health issue worldwide. Some countries with a high prevalence of anaemia also have high prevalence of malaria. Even though Lesotho does not have a high prevalence of malaria, its prevalence rate of anaemia is as high. According to the 2014 Lesotho Demographic and Health Survey (DHS), the prevalence of anaemia among children under- 5 was $51 \%$. Other factors could be influencing the prevalence of anaemia in Lesotho,
\end{abstract}

Objectives: This study examined the household and individual risk factors of anaemia among children under-5 in Lesotho. Methods: Data from the 2014 Lesotho DHS which included 924 children under-5 years were analysed. Descriptive statistics, chi-square cross-tabulations and ordered logistic regression models were run using Stata v15.

Results: Twenty-one percent (21\%) of children under-5 had mild anaemia while $7 \%$ had severe-moderate anaemia. Children residing in households cooking with biogas (aOR=4.88, CI: 1.28-18.58) and those living in households that cook with biomass $(\mathrm{aOR}=4.22$, CI: $1.40-12.67)$ had higher odds of severe-moderate anaemia.

Conclusion: Using solid fuels for cooking increases the vulnerability of children under-5 developing anaemia. Therefore, knowledge of renewable energy resources should be increased. This will help reduce levels of anaemia among under-5 children in Lesotho.

Keywords: Household and individual risk factors, anaemia, under-5 children, Lesotho.

DOI: https://dx.doi.org/10.4314/ahs.v20i3.54

Cite as: Letuka T, Frade S. Household and individual risk factors of anaemia among under-5 cbildren in Lesotho. Afri Health Sci. 2020;20(3): 1478-1486. bttps://dx.doi.org/10.4314/abs.v20i3.54

\section{Introduction}

Anaemia is a major public health issue in most developing countries, specifically in Africa researchers have found that it is more prevalent among children under- $5^{1}$. It is estimated that $43 \%$ of children under-5 are considered anaemic worldwide, and two-thirds are in sub-Saharan Africa ${ }^{2,3}$. The prevalence rate of anaemia among children in most African countries is estimated to be above $40 \%{ }^{4}$. Specifically, in Lesotho, the 2014 Demographic and Health Survey (DHS) reported a $51 \%$ prevalence of anaemia among children under- $5^{5}$. This is a major concern and requires immediate action ${ }^{6}$. Anaemia can lead to severe cognitive development and
Corresponding author:
Teboho Letuka, Faculty of Humanities, Demography and Population Studies, Schools of Social Sciences and Public Health, University of the Witwatersrand, Private bag 3 Wits, 2050, Johannesburg, South Africa. Email: t.dletuka@gmail.com

consequences in growth in young children, which may cause dire health problems in early adulthood ${ }^{7}$

Research has found that half of micronutrients that contribute to the burden of anaemia among children under-5 are due to iron deficiency especially in developing countries ${ }^{7-9}$. However, other studies have found that factors such as nutritional deficiencies and parasitic infections may also cause anaemia ${ }^{10}$. Moreover, studies have continuously shown that factors such as poor water supplies, poor sanitation and the use of biomass fuel are the greatest risk factors of childhood anaemia ${ }^{11,12}$. One study found that in countries that use solid fuel the most, the prevalence of anaemia was 3 times higher than countries that use solid fuels the least ${ }^{13}$. Furthermore, studies show that anaemia is more prevalent among children in rural areas compared to urban areas 7,14. Socio-economic status is also associated with the prevalence of anaemia; with children from poorer and poor households experiencing high prevalence of anaemia compared to those living in more affluent households ${ }^{15}$.

Generally, studies relating to anaemia in Lesotho are limited, however, the few that have been conducted did not address under-5 children ${ }^{16-18}$. One study that did 
address the determinants of anaemia among children under-5 in Lesotho found that stunting, a child's age, the mother's anaemia status, fever in the last two weeks prior to the survey and the mother's body mass index (BMI) were risk factors associated with anaemia ${ }^{9}$. However, this study failed to include household factors in their approach though research has shown that such factors are significantly associated with anaemia among under- 5 children ${ }^{19,20}$.

Countries such as Ghana ${ }^{7}$ and Tanzania ${ }^{21}$ with high anaemia prevalence also have a high prevalence of malaria. However, Lesotho does not have a high malaria prevalence; this means that other factors may be influencing the increase in the prevalence of this disease in Lesotho. Therefore, resources and programs addressing anaemia should be put in place to ensure children's wellbeing. Hence, examining risk factors of anaemia among children under- 5 sheds light on the burden of the disease. This will inform policy and interventions in Lesotho aimed at reducing the prevalence of anaemia. Moreover, a reduction in anaemia would contribute to Lesotho achieving the Sustainable Development Goal (SDG) 3 by 2030, which aims to ensure healthy lives and promote well-being for all at all ages ${ }^{22}$. This study therefore contributes to existing literature on childhood anaemia by examining the combined effect of household and individual risk factors on anaemia among children.

\section{Methods}

\section{Source of data, study design and sampling}

This study analysed secondary data from the 2014 Lesotho DHS. The DHS is conducted every 5 years; the 2014 survey was the third conducted in Lesotho. It provides estimates of demographic and health indicators ${ }^{5}$.
The survey was conducted over a period of 4 months from September to December 2014. The survey used a two-stage sample design which included the cluster sampling of enumeration areas and the systematic sampling of households ${ }^{5}$. The sampling frame for the 2014 Lesotho DHS is an updated version of the 2006 Lesotho Population and Housing Census. Households were listed and those to be included in the survey were randomly selected in all the enumeration areas (EAs). About 25 households were selected from each sample point ${ }^{5}$.

The study population of this research were children under five years born to women of reproductive age (15-49) in Lesotho. All women aged 15-49 who were either permanent residents of the selected households or were visitors who had stayed in the household the night before the survey were eligible for interviews. Therefore, all children born to these eligible women were also eligible to be included in the survey ${ }^{5}$. For the purpose of this study, the children recode file of the DHS was used. The sample size for this file was 3,138. Because the study examined the household factors, respondents who were not permanent residents of the household were excluded from the study. Also, children who were not living with the respondent were excluded so that outcomes would be inferred to the characteristics of the household. Because the World Health Organisation (WHO) considers children aged 6-59 months with a haemoglobin level less than $11.0 \mathrm{~g} / \mathrm{d}$ anaemic ${ }^{6}$, children under 6 months were excluded from this study. Furthermore, children with missing data were excluded from this study. After data processing and cleaning, the weighted sample size for this study reduced to 924. Figure 1 presents the exclusion criteria for this study.

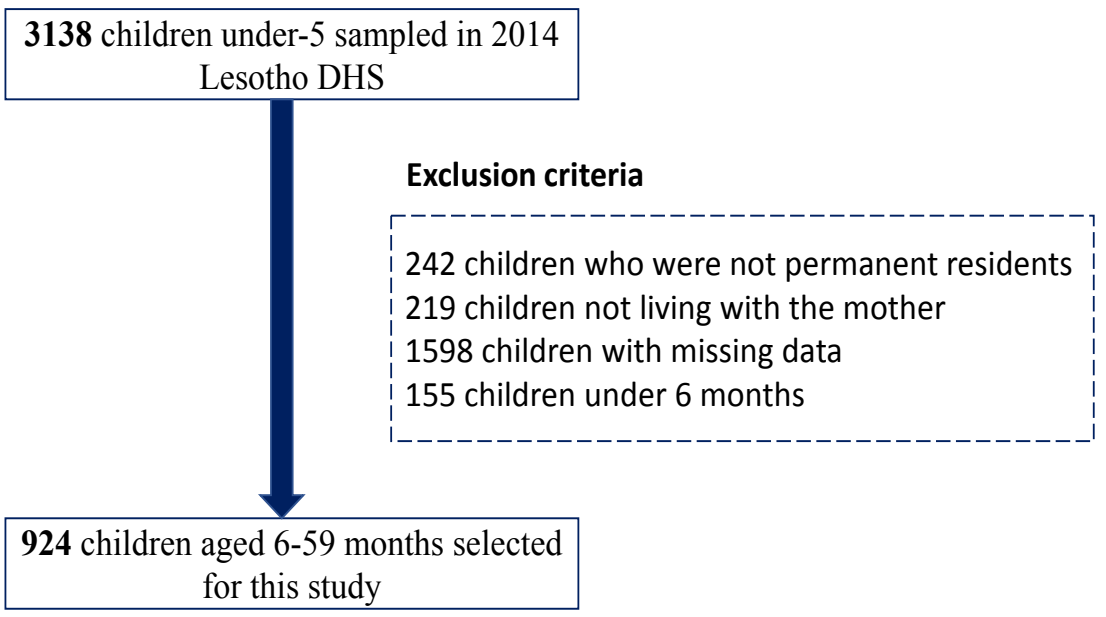

Figure 1. Study sampling procedure 


\section{Tests for anaemia}

Anaemia was tested from all children aged 6-59 months for whom consent was obtained from legal guardians. This was done through drawing blood from a heel prick on children aged 6-11 months and finger prick on children above 11 months ${ }^{5}$ the blood samples were collected using a microcuvette. Haemoglobin analysis was carried out on-site using a battery-operated portable HemoCue analyser.

\section{Study variables \\ Outcome variable}

Anaemia was the outcome variable of the study. Anaemia as defined by the DHS was; severe anaemia $(<7.0$ $\mathrm{g} / \mathrm{dl})$, moderate anaemia $(7.0-9.9 \mathrm{~g} / \mathrm{dl})$, mild anaemia $(10.0-10.9 \mathrm{~g} / \mathrm{dl})^{5}$. This study adapted the definition of anaemia as per DHS $2014^{5}$. In the data set, anaemia was categorised as "not anaemic (72.4\%)", "mild (21\%)", "moderate $(5.6 \%)$ " and "severe (1.1\%)", however, for the purpose of this study anaemia was categorised as "not anaemic", "mild" and "severe-moderate". The categories "moderate" and "severe" were combined because of the lower percentages depicted in each category. This is also how another researcher categorised anaemia in his study ${ }^{19}$.

\section{Independent variables}

The independent variables included in this study were the household and individual factors. These were; source of drinking water, type of toilet facility, type of cooking fuel, type of place of residence, household wealth index (proxy for socio-economic status), exposure to mass media, number of under- 5 children in households, and occurrence of diarrhoea. Table 1 presents the definition of the study variables.

Table 1. Description of study variables. (LDHS, 2014)

\begin{tabular}{|l|l|}
\hline Variable & Description from DHS \\
\hline Anaemic & Children with a haemoglobin less than 11.0 g/dl \\
\hline Source of drinking water & $\begin{array}{l}\text { What is the main source of drinking water for members } \\
\text { of your household? }\end{array}$ \\
\hline Type of toilet facility & $\begin{array}{l}\text { What kind of toilet facility do members of your } \\
\text { household usually use? }\end{array}$ \\
\hline Type of cooking fuel & $\begin{array}{l}\text { What type of fuel does your household mainly use for } \\
\text { cooking? }\end{array}$ \\
\hline Type of residence & Rural or urban \\
\hline Household wealth index & $\begin{array}{l}\text { Households are given scores based on the number and } \\
\text { kinds of consumer goods they own. Scores are derived } \\
\text { using principal component analysis to derive wealth } \\
\text { quintiles. This ranges from poorer to richer }\end{array}$ \\
\hline Exposure to mass media & $\begin{array}{l}\text { Does your household have a radio or TV in working } \\
\text { condition? (Yes/No) }\end{array}$ \\
\hline Number of under-5 children in households & Number of children 5 and under in household \\
\hline Occurrence of diarrhoea & Has child had diarrhoea in the last 2 weeks? (Yes/No) \\
\hline
\end{tabular}

\section{Data analysis}

Data was analysed using Stata version 15. The main objective of this study was to examine the household and individual risk factors of anaemia among children under- 5 in Lesotho. Before this could be done, descriptive statistics were conducted on all study variables to describe the characteristics of the study population. In order to address the main objective, two specific objectives were considered: (1) To examine the extent to which the level of anaemia among children under- 5 varies across household and individual factors in Lesotho. This was done using cross-tabulations; the chi square test was then used to detect the significance of the associations (see table 3 ).
(2) To identify household and individual risk factors of anaemia among children under-5 in Lesotho. To address this objective, the unadjusted and adjusted logistic regression models were used. The ordered logistic regression model was chosen because the outcome variable (anaemia) in this study was categorised into ranked categories ranging from lowest to highest. Variables that were found to be statistically associated with anaemia through the chi square test (to address objective 1) were included in the regression models. Table 3 shows that type of cooking fuel, exposure to mass media and under-5 children in households were significantly associated with anaemia among under-5 children, so they were included in the regression models. However, var- 
iables such as place of residence, household wealth index, occurrence of diarrhoea, type of toilet facility and source of drinking water were excluded from the regression models as they were not statistically associated with anaemia. The equation for the models are described below:

Unadjusted models: considered each variable and anaemia. The logistic regression equation for the unadjusted models was modelled as follows:

$\mathrm{Ln}=\beta 0+\beta \mathrm{s} X \mathrm{~s}$

Where: $\beta 0=$ intercept of the regression model $\beta s=$ the regression coefficients for the variables $\mathrm{Xs}=$ the variables

Adjusted model: all-inclusive model which incorporated all the study variables into the multilevel analysis. The logistic regression equation for the adjusted model was modelled as follows:

$\mathrm{Ln}=\beta 0+(\beta a \mathrm{Xaz}+\beta a z 2 \mathrm{Xaz} 2+\beta 1 \mathrm{X} 1+\beta 2 \mathrm{X} 2 \ldots+\beta \mathrm{pXp})$ Where: $\beta 0=$ intercept of the regression model

$\beta \mathrm{s}=$ the regression coefficient for the type of cooking fuel, exposure to mass media and under- 5 children in households

$\mathrm{Xs}=$ are the control variables.

Overall there were 4 regression models fitted in this study. Results were interpreted using odds ratios (OR), where an $\mathrm{OR}>1$ indicated a higher risk, $\mathrm{OR}<1$ indicated a lower risk and $\mathrm{OR}=1$ indicated no difference. Moreover, the level of significant was set at $\mathrm{p}<0.05$ and the confidence interval (CI) of $95 \%$ was used.

\section{Ethical considerations}

This study used secondary data therefore did not require any ethical approval. However, the 2014 Lesotho DHS protocol was reviewed and approved by the Lesotho Ministry of Health Research and Ethics Committee and the Institutional Review Board of ICF Internation$\mathrm{al}^{5}$. Additionally, no personal information or respondent's names were identified in the dataset, therefore, anonymity and confidentiality of the respondents were guaranteed.

\section{Results}

\section{General characteristics of the population}

There were 924 children under- 5 in this study; the majority $(70 \%)$ resided in rural areas. Table 2 shows that most of the children $(62 \%)$ were living in households that used biomass as a means of fuel for cooking compared to other fuels. Furthermore, more than half (57\%) of children lived in households using pit latrines. Table 2 also shows that more than half $(69 \%)$ of children lived in households that used tap water for drinking, however, 18\% lived in households that drank water from unprotected wells and springs. It can also be observed that $41 \%$ of the children in this study resided in rich households. Moreover, more than half $(55 \%)$ of households have access to a radio, while only $10 \%$ have a TV and $34 \%$ have access to both a TV and a radio. More than half $(55 \%)$ of the households in this study have only one child. Approximately 13\% of children in the study have experienced recent episodes of diarrhoea. Figure 2 shows the levels of anaemia among children under-5 in Lesotho. It is observed that although $72 \%$ of under- 5 children were not anaemic, $21 \%$ had mild anaemia while $7 \%$ had moderate-severe anaemia. 
Table 2. Weighted frequency and percentage distribution of children under-5 in Lesotho by household-environmental factors. (LDHS, 2014)

\begin{tabular}{|c|c|}
\hline Background Characteristics & $\begin{array}{c}\text { Total, n (\%) } \\
\text { N=924 }\end{array}$ \\
\hline \multicolumn{2}{|l|}{ Type of cooking fuel } \\
\hline Electricity & $83(9)$ \\
\hline LPG & $195(21.2)$ \\
\hline Biogas & $29(3.1)$ \\
\hline Kerosene & $42(4.6)$ \\
\hline Biomass & $575(62.1)$ \\
\hline \multicolumn{2}{|l|}{ Type of toilet facility } \\
\hline Flush & $9(1.1)$ \\
\hline VIP & $144(15.5)$ \\
\hline Pit latrine & $526(56.9)$ \\
\hline No facility & $245(26.5)$ \\
\hline \multicolumn{2}{|l|}{ Source of drinking water } \\
\hline Tap water & $640(69.3)$ \\
\hline Borehole & $47(5)$ \\
\hline Protected well and spring & $61(6.6)$ \\
\hline Unprotected well and spring & $168(18.1)$ \\
\hline Other sources & $8(1)$ \\
\hline \multicolumn{2}{|l|}{ Place of residence } \\
\hline Urban & $276(29.9)$ \\
\hline Rural & $648(70.1)$ \\
\hline \multicolumn{2}{|l|}{ Household wealth index } \\
\hline Poor & $348(37.7)$ \\
\hline Middle & $199(21.5)$ \\
\hline Rich & $377(40.8)$ \\
\hline \multicolumn{2}{|l|}{ Exposure to mass media } \\
\hline Household has TV & $60(10.3)$ \\
\hline Household had Radio & $328(55.4)$ \\
\hline Household has both & $203(34.3)$ \\
\hline \multicolumn{2}{|c|}{ Number of children under-5 in household } \\
\hline 1 child & $504(54.5)$ \\
\hline 2 children & $330(35.8)$ \\
\hline 3-5 children & $90(9.7)$ \\
\hline \multicolumn{2}{|l|}{ Had diarrhoea recently } \\
\hline No & $802(86.8)$ \\
\hline Yes & $122(13.2)$ \\
\hline
\end{tabular}

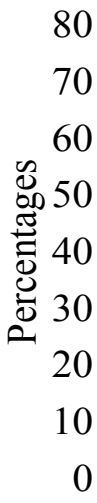

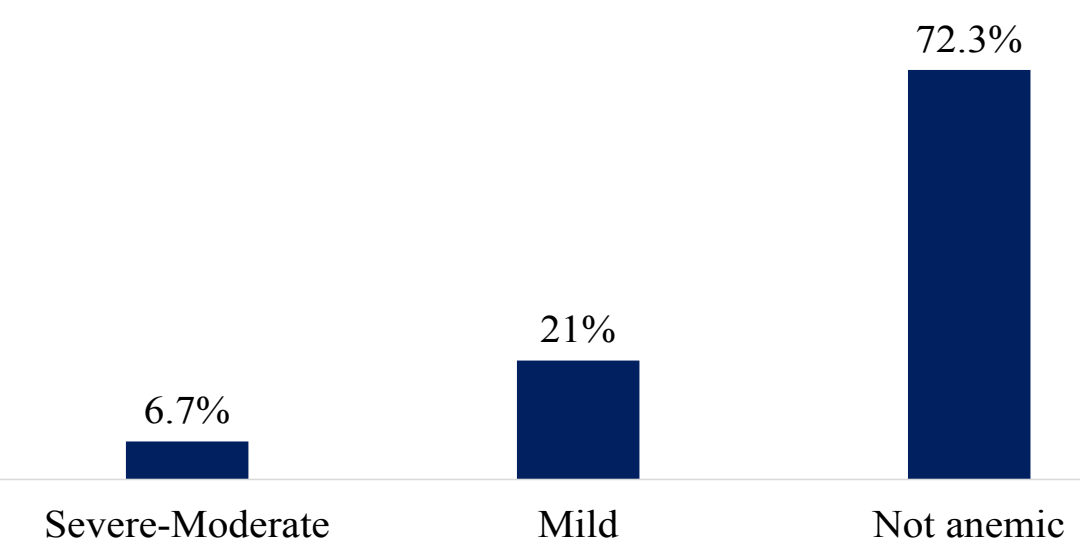

Level of anaemia

Figure 2. Level of anaemia among children under-5 in Lesotho (LDHS, 2014) 
Extent of the level of anaemia among under-5 children across household and individual factors in Lesotho

Table 3 presents the variation in the level of anaemia across household and individual factors. It shows that exposure to mass media was statistically associated with anaemia. Children living in households that had both a TV and radio had higher levels of mild anaemia compared to children living in households that either has a TV or Radio. Moreover, $32 \%$ of children residing in households with 3-5 children had mild anaemia while
$8 \%$ of children living in households with only 2 children had severe-moderate anaemia. This relationship was statistically significant. Furthermore, $27 \%$ of children residing in households with electricity had mild anaemia compared to $15 \%$ who had severe-moderate anaemia. Type of cooking fuel was found to be statistically associated with anaemia. However, type of toilet facility, source of drinking water, occurrence of diarrhoea, household wealth index and place of residence were not found to be statistically associated with anaemia therefore were not included in the regression models.

Table 3. Levels of anaemia among children under-5 in Lesotho across household and individual factors (LDHS, 2014)

\begin{tabular}{|c|c|c|c|c|}
\hline Characteristics & $\begin{array}{c}\text { Not anaemic } \\
\text { N (\%) }\end{array}$ & $\begin{array}{c}\text { Mild } \\
\text { N (\%) }\end{array}$ & $\begin{array}{c}\text { Severe-Moderate } \\
\text { N (\%) }\end{array}$ & p-value \\
\hline \multicolumn{2}{|l|}{ Place of residence } & & & 0.425 \\
\hline Urban & $168(72.4)$ & $47(20.3)$ & $17(7.3)$ & \\
\hline Rural & $521(76.4)$ & $123(18.0)$ & $38(5.6)$ & \\
\hline \multicolumn{3}{|l|}{ Household wealth index } & & 0.373 \\
\hline Poor & $320(77.9)$ & $70(17.0)$ & $21(5.1)$ & \\
\hline Middle & $147(76.2)$ & $33(17.1)$ & $13(6.7)$ & \\
\hline Rich & $222(71.6)$ & $67(21.6)$ & $21(6.8)$ & \\
\hline Exposure to mass media* & & & & 0.053 \\
\hline Household has TV & $41(77.3)$ & $8(15.1)$ & $4(7.6)$ & \\
\hline Household has Radio & $260(81.0)$ & $47(14.6)$ & $14(4.4)$ & \\
\hline Household has Both & $119(69.1)$ & $40(23.3)$ & $13(7.6)$ & \\
\hline Number of children under-5 in household* & & & & 0.008 \\
\hline 1 child & $399(77.4)$ & $90(17.5)$ & $26(5.1)$ & \\
\hline 2 children & $240(74.8)$ & $55(17.1)$ & $26(8.1)$ & \\
\hline $3-5$ children & $50(64.1)$ & $25(32.1)$ & $3(3.8)$ & \\
\hline Had diarrhoea recently & & & & 0.473 \\
\hline Yes & $94(79.7)$ & $19(16.1)$ & $5(4.2)$ & \\
\hline No & $595(74.8)$ & $151(18.9)$ & $50(6.3)$ & \\
\hline Type of cooking fuel* & & & & 0.005 \\
\hline Electricity & $43(58.1)$ & $20(27.0)$ & $11(14.9)$ & \\
\hline$\overline{L P G}$ & $101(72.1)$ & $33(23.6)$ & $6(4.3)$ & \\
\hline Biogas & $26(78.8)$ & $6(18.2)$ & $1(3.0)$ & \\
\hline Kerosene & $29(76.3)$ & $8(21.1)$ & $1(2.6)$ & \\
\hline Biomass & $490(77.9)$ & $103(16.4)$ & $36(5.7)$ & \\
\hline \multicolumn{3}{|l|}{ Type of toilet facility } & & 0.460 \\
\hline Flush & $8(72.7)$ & $2(18.2)$ & $1(9.1)$ & \\
\hline VIP & $114(73.1)$ & $36(23.1)$ & $6(3.8)$ & \\
\hline Pit latrine & $336(74.3)$ & $87(19.3)$ & $29(6.4)$ & \\
\hline No facility & $231(78.3)$ & $45(15.3)$ & $19(6.4)$ & \\
\hline \multicolumn{3}{|l|}{ Source of drinking water } & & 0.070 \\
\hline Tap water & $462(74.3)$ & $124(19.9)$ & $36(5.8)$ & \\
\hline Borehole & $29(76.3)$ & $4(10.5)$ & $5(13.2)$ & \\
\hline Protected well/spring & $43(69.4)$ & $16(25.8)$ & $3(4.8)$ & \\
\hline Unprotected well/spring & $148(81.8)$ & $24(13.3)$ & $9(4.9)$ & \\
\hline Other source & $7(63.6)$ & $2(18.2)$ & $2(18.2)$ & \\
\hline
\end{tabular}

${ }^{*} \mathrm{p}<0.005=$ category significance 
Household and individual factors associated with anaemia among children under-5 in Lesotho

Table 4 presents results from the univariate and multivariate ordered logistic regression models. Living in households that cook with biogas has higher risk of anaemia for children under-5. This is reflected by higher odds of anaemia in both the unadjusted $(\mathrm{uOR}=4.81$, CI: 1.36-17.01) and adjusted (aOR=4.88, CI:1.28-18.58) models. The unadjusted models show that liquified petroleum gas (LPG) is not statistically associated with anaemia (uOR=2.05, CI:0.92-4.56), however, when adjusted for other variables the significance of LPG changes $(\mathrm{aOR}=2.69, \mathrm{CI}: 1.03-7.06)$. This may mean that the inclusion of other variables in the model may be enhancing the risk of anaemia among children living in households that cook with LPG. Children residing in households cooking with LPG were 2.7 times more likely to be severely-moderately anaemic versus not anaemic and mildly anaemic compared to those living in households that cooked with electricity while controlling for other factors $(\mathrm{aOR}=2.7, \mathrm{CI}: 1.03-7.06)$.

Table 4. The unadjusted and adjusted odds ratios from the ordered logistic regression model of the association between household, individual factors and anaemia among children under-5 in Lesotho. (LDHS, 2014.)

\begin{tabular}{|c|c|c|c|c|}
\hline \multirow[t]{2}{*}{ Characteristics } & \multicolumn{2}{|c|}{ Univariate Models } & \multirow{2}{*}{$\begin{array}{c}\text { Multivariate } \\
\text { aOR }\end{array}$} & \multirow{2}{*}{$\begin{array}{c}\text { Model } \\
95 \% \text { CI }\end{array}$} \\
\hline & uOR & $95 \% \mathrm{CI}$ & & \\
\hline \multicolumn{5}{|l|}{ Type of cooking fuel } \\
\hline Electricity & 1 & & 1 & \\
\hline LPG & 2.05 & $0.92-4.56$ & 2.69 & $1.03-7.06^{* *}$ \\
\hline Biogas & 4.81 & $1.36-17.01^{* *}$ & 4.88 & $1.28-18.58 * *$ \\
\hline Kerosene & 2.60 & $1.12-6.06^{* *}$ & 2.14 & $0.74-6.21$ \\
\hline Biomass & 3.33 & $1.29-8.61^{* *}$ & 4.22 & $1.40-12.67^{* *}$ \\
\hline \multicolumn{5}{|c|}{ Exposure to mass media } \\
\hline Household has TV & 1 & & 1 & \\
\hline Household has radio & 1.66 & $0.54-5.11$ & 1.33 & $0.43-4.11$ \\
\hline Household has both & 0.97 & $0.27-3.48$ & 1.21 & $0.37-3.99$ \\
\hline \multicolumn{5}{|c|}{ Under-5 children in household } \\
\hline 1 child & 1 & & 1 & \\
\hline 2 children & 0.63 & $0.39-1.01$ & 0.58 & $0.30-1.11$ \\
\hline 3-5 children & 0.58 & $0.34-0.99^{* *}$ & 0.59 & $0.31-1.11$ \\
\hline
\end{tabular}

\section{Discussion}

This study examined the household and individual risk factors of anaemia among children under-5 in Lesotho. This was done by addressing 2 specific objectives; (1) To examine the extent to which the level of anaemia among children under- 5 varies across household and individual factors in Lesotho. (2) To identify household and individual risk factors of anaemia among children under-5 in Lesotho. In addressing the first specific objective, this study found that mild anaemia was more widespread compared to severe-moderate anaemia. Levels of mild anaemia were higher among children residing in households that cooked with LPG, used VIP toilets and those who drank water from wells/springs. Some researchers argue that mild anaemia is often asymptomatic and therefore it may remain undetected and untreated ${ }^{14}$. These findings support research that has shown that these conditions affect anaemia among children under-5 ${ }^{8,11,12}$.

While identifying household and risk factors of anaemia, this study found that cooking with solid fuels increased the odds of anaemia among children under-5. The relationship between type of cooking fuel and anaemia among children under-5 was very eminent. It appeared that the use of biogas and biomass for cooking increased the likelihood of anaemia. It may be possible that majority of households in Lesotho continue to use solid fuels opposed to electricity. Research has shown that most households in Lesotho, especially in rural areas do not have access to electricity and that 
some households may perceive electricity to be more expensive as opposed to traditional biomass ${ }^{23}$. These results were in concordance with various studies that have found that the use of solid fuels increases the likelihood of anaemia among children under- $5^{13,24}$.

Other factors included in the study such as type of toilet facility, source of drinking water, occurrence of diarrhoea, household wealth index and place of residence were not significantly associated with anaemia among children under-5 in Lesotho.

\section{Limitations}

Because this study analysed cross-sectional secondary data, the generated results could not infer causation. Also, children with missing information were excluded from this study therefore reducing the sample size. A small sample may prevent the study findings from being extrapolated to the overall population ${ }^{25}$. Despite such limitations the study included sampling weights which accounted for the reduced sample size in order to be more representative of the study population. Moreover, the 2014 Lesotho DHS does not provide information on the current health status of children, which might have biased the results. Research has shown that recent illnesses affect the levels of anaemia among young children ${ }^{12}$. Therefore, if not addressed they may become confounding factors influencing results.

\section{Conclusion and recommendations}

Despite these limitations, this study has established a significant association between household factors and anaemia among children under-5 in Lesotho. Specifically, the use of solid fuels in cooking and had a greater likelihood of anaemia when compared to cooking using electricity. These findings also draw interest into the different types of cooking fuels that are used in households in Lesotho, and this may be related across the globe where the usage of the type of cooking fuel used in most households differs from country to country. Prior research has shown that most developing countries continue to use solid fuels for cooking. The benefit of the usage of clean fuels for cooking has been found to greatly reduce the prevalence of anaemia among children.

Given the high levels of solid fuels usage among households in Lesotho and its established association between anaemia among children under-5, this paper can be used as an information tool to support the Lesotho Energy Policy (2015-2022) ${ }^{26}$. In educating people of the importance of the use of cleaner fuels, the policy will indirectly work towards reducing anaemia among children under-5 in Lesotho. Moreover, this research should encourage future studies on the use of solid fuels for cooking and the impact it has on child health in Lesotho. However, considering that this study was limited in its ability to establish causality, future research may need to explore this relationship using longitudinal data collected over a large period of time in order to detect notable changes. A better understanding of fuel usage in households can undeniably lead to the development of interventions and policies that can reinforce proper fuel usage and therefore significantly reduce the prevalence of anaemia.

\section{Competing interests}

The authors declare that they have no competing interest

\section{Acknowledgements}

The authors would like to thank the DHS for the provision of the dataset and peers in the Demography and Population Studies department at the University of the Witwatersrand for their critical advice and encouragement.

\section{References}

1. Khan, J. R., Awan, N., \& Misu, F. (2016). Determinants of anemia among 6-59 months aged children in Bangladesh: evidence from nationally representative data. BMC Pediatrics, 16. https://doi.org/10.1186/ s12887-015-0536-Z

2. Simbauranga RH, Kamugisha E, Hokororo A, Kidenya BR, Makani J. Prevalence and factors associated with severe anaemia amongst under-five children hospitalized at Bugando Medical Centre, Mwanza, Tanzania. BMC Hematol. 2015 Oct 12;15(1):13.

3. Woldie, H., Kebede, Y., \& Tariku, A. (2015). Factors Associated with Anemia among Children Aged 6-23 Months Attending Growth Monitoring at Tsitsika Health Center, Wag-Himra Zone, Northeast Ethiopia. Journal of Nutrition and Metabolism, 2015. https://doi. org/10.1155/2015/928632

4. Gebreegziabiher G, Etana B, Niggusie D. Determinants of Anemia among Children Aged 6-59 Months Living in Kilte Awulaelo Woreda, Northern Ethiopia [Internet]. Anemia. 2014[cited2019Mar16]. Availablefrom: https://www.hindawi.com/journals/ anemia/2014/245870/

5. Ministry of Health [Lesotho] and ICF International. 2016. Lesotho Demographic and Health Survey 2014. Maseru, Lesotho: Ministry of Health and ICF International. Retrieved from https://dhsprogram.com/ publications/publication-fr309-dhs-final-reports.cfm 
6. WHO. (2008). WHO | Worldwide prevalence of anaemia 1993-2005. Retrieved March 21,2018,fromhttp://www.who.int/nutrition/publications/micronutrients/anaemia_iron_deficiency/9789241596657/en/ 7. Ewusie JE, Ahiadeke C, Beyene J, Hamid JS. Prevalence of anemia among under-5 children in the Ghanaian population: estimates from the Ghana demographic and health survey. BMC Public Health. 2014 Jun 19;14(1):626.

8. Ncogo, P., Romay-Barja, M., Benito, A., Aparicio, P., Nseng, G., Berzosa, P., ... Herrador, Z. (2017). Prevalence of anemia and associated factors in children living in urban and rural settings from Bata District, Equatorial Guinea, 2013. PLoS One, 12(5). https://doi. org/10.1371/journal.pone.0176613

9. Gaston, R. T., Ramroop, S., \& Habyarimana, F. (2018). Determinants of factors associated with anemia among children under five years in Lesotho. African Population Studies, 32(1). Retrieved from http://aps.journals. ac.za/pub/article/view/1154

10. Menon, M. P., \& Yoon, S. S. (2015). Prevalence and Factors Associated with Anemia Among Children Under 5 Years of Age-Uganda, 2009. The American Journal of Tropical Medicine and Hygiene, 93(3), 521-526. https://doi.org/10.4269/ajtmh.15-0102

11. Baranwal, A., Baranwal, A., \& Roy, N. (2014). Association of Household Environment and Prevalence of Anemia Among Children Under-5 in India. Frontiers in Public Health, 2. https://doi.org/10.3389/ fpubh.2014.00196

12. Moschovis, P. P., Wiens, M. O., Arlington, L., Antsygina, O., Hayden, D., Dzik, W., ... Hibberd, P. L. (2018). Individual, maternal and household risk factors for anaemia among young children in sub-Saharan Africa: a cross-sectional study. BMJ Open, 8(5), e019654. https://doi.org/10.1136/bmjopen-2017-019654

13. Accinelli, R. A., \& Leon-Abarca, J. A. (2017). Solid fuel use is associated with anemia in children. Environmental Research, 158,431-435. https://doi.org/10.1016/j.envres.2017.06.032 14. Kuziga, F., Adoke, Y., \& Wanyenze, R. K. (2017). Prevalence and factors associated with anaemia among children aged 6 to 59 months in Namutumba district, Uganda: a cross- sectional study. BMC Pediatrics, 17. https://doi.org/10.1186/s12887-017-0782-3

15. Goswmai S, Das KK. Socio-economic and demographic determinants of childhood anemia. J Pediatr (Rio J). 2015 Sep 1;91(5):471-7.

16. Oguntibeju, O. O. (2003). Parasitic Infestation and Anaemia : The Prevalence in a Rural Hospital Setting, 3. Retrieved from http://medind.nic.in/jac/t03/ i3/jact03i3p210.pdf
17. Yasutake, S., He, H., Decker, M. R., Sonenstein, F. L., \& Astone, N. M. (2013). Anemia among Adolescent and Young Women in Low-and-Middle-Income Countries. International Journal of Child Health and Nutrition, 2(2), 105-112-112.

18. Mugomeri, E., Musa, N. K., \& Chatanga, P. (2016). Heamoglobin response to routine iron and folate supplementation during pregnancy in an HIV-endemic rural area roma, Lesotho. Medical Technology $S A$, 30(1), 10-14.

19. Muchie, K. F. (2016). Determinants of severity levels of anemia among children aged 6-59 months in Ethiopia: further analysis of the 2011 Ethiopian demographic and health survey. BMC Nutrition, 2(1), 51. https://doi.org/10.1186/s40795-016-0093

20. Kawo, K. N., Asfaw, Z. G., \& Yohannes, N. (2018). Multilevel Analysis of Determinants of Anemia Prevalence among Children Aged 6-59 Months in Ethiopia: Classical and Bayesian Approaches [Research article]. https://doi.org/10.1155/2018/3087354

21. Kejo, D., Petrucka, P. M., Martin, H., Kimanya, M. E., \& Mosha, T. C. (2018). Prevalence and predictors of anemia among children under 5 years of age in Arusha District, Tanzania. Pediatric Health, Medicine and Therapeutics,9,9-15. https://doi.org/10.2147/PHMT. S148515

22. UNDP. (2017). Sustainable Development Goals. Retrieved March 16, 2019, from UNDP website:https://www.undp.org/content/undp/en/home/ sustainable-development-goals.html

23. Mpholo, M., Meyer-Renschhausen, M., Thamae, R. I., Molapo, T., Mokhuts'oane, L., Taele, B. M., \& Makhetha, L. (2018). Rural Household Electrification in Lesotho. In Moeketsi Mpholo, D. Steuerwald, \& T. Kukeera (Eds.), Africa-EU Renewable Energy Research and Innovation Symposium 2018 (RERIS 2018) (pp. 97-103). Springer International Publishing.

24. Danaei, G., Andrews, K. G., Sudfeld, C. R., Fink, G., McCoy, D. C., Peet, E., ... Fawzi, W. W. (2016). Risk Factors for Childhood Stunting in 137 Developing Countries: A Comparative Risk Assessment Analysis at Global, Regional, and Country Levels. PLOS Medicine, 13(11), e1002164. https://doi.org/10.1371/journal. pmed.1002164

25. Faber, J., \& Fonseca, L. M. (2014). How sample size influences research outcomes. Dental Press Journal of Orthodontics, 19(4), 27-29. https://doi. org/10.1590/2176-9451.19.4.027-029.ebo

26. LesothoEnergyPolicy(2015-2025).Accessedat: https://www.solarthermalworld.org/sites/gstec/files/ news/file/2016-03-10/lesotho_energy_policy_.pdf 